\title{
Losing of Local Identity in Rapid Developing China
}

\author{
Yu-Han SHAO ${ }^{1, a}$, Bin-Yi LIU 2,b \\ ${ }^{1,2}$ Department of Landscape, College of Architecture and Urban Planning, Tongji University, \\ No. 1239 Siping Road, YangpuDistrict, Shanghai, China, 200092 \\ ashaoyuhan7@hotmail.com, bbyltjulk@vip.sina.com
}

Keywords: Local Identity, Landscape, Chinese Urban Development

\begin{abstract}
This study provided a formal discussion on the importance ofthe term "Local Identity" in the field of landscape study and the problem of losing of such identity in Chinese urban development. The study first introduces the definition of local identity in landscape research. Then discuss the problem that China is facing in terms of losing such identity. The paper concludes by suggestingthe important meanings of local identity in Chinese landscape development and proposing ideas that could help to contribute to resolve such issue.
\end{abstract}

\section{Introduction}

In the urban development process, identity has been recognized as a vital factor with which a region can build a close relationship with their citizens and businesses through pride[1]. It also has the ability to provide landscape uniqueness in modern landscape development processes [2]. Identifying such identities can help practitioners to improve the image of the city towards the desired quality, therefore distinguish the city from other towns and regions in the global competition, which will enhance citizens' sense of belonging and attract skilled people and investments.

Identity is a dynamic process of changing surrounding factors, such as environment and time [3, 4]. Deffnerpointed out that identity is also related to the historical heritage and the traditional characteristics of the region [5]. Therefore identity providescontinuity for development, preserving the historical traditions of local communities as the city changes over time; most importantly it provides possibilities for urban rehabilitation to develop a sense of home, security and community for the local residents. Hence, local identity is a combination of social, economic, historical and political processes [6].Withglobalisation, such identity has been lost due to the urban development process, and the loss of uniqueness has become a common problem that fast changing environment are facing, especially in fast developing countries, China is a typical example.Therefore the goal of this essay is to introduce the importance of local identity, in relation to help Chinese practitioners to better protect the uniqueness for urban places.

\section{Importance of Local Identity}

Based on physical site scale in landscape study, identities have been introduced as: national identity, regional identity, urban identity and local identity [7]. National identity is commonly recognised as a country or a nation [8]. Whereas the regional identity focuses more on how people interact with their environment from a smaller scale compared to a country and people's lives in the same region tend to share a similar language and religion, a province for example [9]. From a historical point of view, regional identity focuses on a more narrative range of people compared with national identity. It is a 'mental' reflection of the space in people's minds and memories [10]. The urban identity narrows the area down to a more specific city level. e.g. the city of Beijing. Urban identity focuses more on how local people interact and therefore forms its own identity, which then forms the regional identity [11]. Finally, local identity acts as a basic principle for all three former identities. It focuses on people who participate in a very narrative scale of area, e.g. a neighborhood in a city. It focuses on how people interact with the local environment. 
Local identity is an important contributor to the quality of life for people, especially in local areas; it acts as an important aspect in urban landscape development. Local identity can also provide distinctiveness to the local area that differentiates itself from outside areas from four major aspects: Physical, Social, Sensory and Memory [12].It is supported that the physical aspect is one of the major aspects in local identity. Besides local identity also focuses on how people contribute to the environment to make the place more attractive and distinguished to the outside world, from this perspective social activity is important in which local people interact with their place to make it unique $[13,14,15]$. As users are a key attribute of urban places, local identity is not only about the uniqueness of the physical place and its functionality, but also the ability to provide psychological comfort - Sensory $[16,17]$. An important part of an area is its inheritance from its past, which is a benefit of a traditional community having long dwelt there [18]. These are usually expressed through physical and spiritual heritage, which are deeply embedded with human memory.

\section{The Loss of Local Identity in China}

Apart from introducing the importance of local identity to help people understand and realise its importance, this paper is trying to contribute to the broader problem --- the loss of local identity in urban places, more specifically--- China.

\section{Globalisation, Modernisation and Westernisation Effect}

Due to the globalisation effect, urban places havemodernised in a robust pace in the last 10 years, and during that period, cities, which used to have only minor connections to the global community, are now deeply intertwined with global influence. Globalisation has strong effects on the physical development of cities as more and more cities start to build up their own places by copying other successful cities, which results in a considerable amount of cities beingalike, sometimes even identical. With the globalisation process, the gradual formation of a single type of living environment is making the cities monotonous.Areas become increasingly similar with similar architecture and urban squares [19]. While these areas are designed for a global audience, the fact that physical development is geographically fixed means it is also often used and given meaning by local residents. Globalisation therefore results in the destruction of the dominant culture. However, there has been much research on the possibility of merging these influences to create areas that have a hybridised identity that is both local and global. There is also research that argues that globalisation does not represent the end of local distinction, but instead offers a broader scale of influences that affect identity and place, bringing together global and local influences [20]. They suggest that globalisation encourages local areasto react to public pressure to create a place that better meets the needs and desires of the residents, thus, extending the identity of the city and not simply extorting or negating it. Such hybridised identity can be achieved through both the physical design and the narratives associated with the physical reality.

Place is defined by Relph to be an entity which gained its meanings through its historical continuity, unique character, and opportunity for rest [21]. However, considering the increased mobility, globalisation, growing homogeneity of places and the loss of their cultural specificity, the meaningful relations between people and place face the threat of being destroyed. In places affected by globalisation, western countries have noticed the loss of each city's unique identity and started to either protect the identity or further develop it to make the city stand out. Such cities, have adopted strategies and initiatives to limit the negative effects of cultural globalisation, and increase a sense of individuality and distinctiveness. The first National Place Identity Conference took place in Manchester on $2^{\text {nd }}$ October 2009 and was the first event to bring together urban designers, economic development officers and tourism professionals to debate the importance of identity for urban places. The event was concentrating on the improvements of the character of individual areas, and initiatives that enhance local identity together with effective marketing strategy to fulfill the 
maximum benefits on investment realised from the local area. This move explicitly expressed the concerns of western countries on the loss of local identity.

However, there are still countries that have not yet realised loss of their unique elements and focus on constantly redeveloping the city to match the developed countries. Among those cities that are losing their unique identity during the modernisation, China is a typical example [22]. How to create local identity in rapidly developing Chinese cities is a difficult but fundamental and contemporary issue. Due to the discontinuity of historical, cultural and social structures created by colonisation, modernisation and globalisation, and people's indifference to their own cultural, historic and social heritage, locality is being rapidly lost in China [23].During the process of modernisation China tried to copy western elements without much reflection. Thus the discontinuity of tradition led to disorder in the urban landscape. Due to urbanisation as result of population growth and economic development after the Second World War, medium and high-rise buildings have been abruptly introduced to Chinese cities. All the natural elements have been put aside for roads for traffic and other infrastructure required by contemporary urban development $[24,25,26]$.

\section{Urban Development are Centralised to the Same Policy, Law and Process}

In China, the developments of cities are centralised to the government policy- "Urban and Rural Planning Law of the People's Republic of China”. This is the first layer of urban control governing in China. The urban planning system is centralised so that every city in the entire country is built according to the same law. Due to the effect of all the planning works being based upon the same legislation, Cities in China tend to develop in very similar ways, which makes it very difficult for them to differentiate themselves with others. Figure 1 represents the typical four-step reconstruction process in China: Original old landscape; Destroy the old landscape; Reconstruction; Refined new landscape. The figures show the urbanisation process in China, which got applied uniformly across all Chinese cities. Because the focus is on the standard process, the originality and heritage characteristics have been vastly destroyed and resulted in similar districts or cities across the whole country.
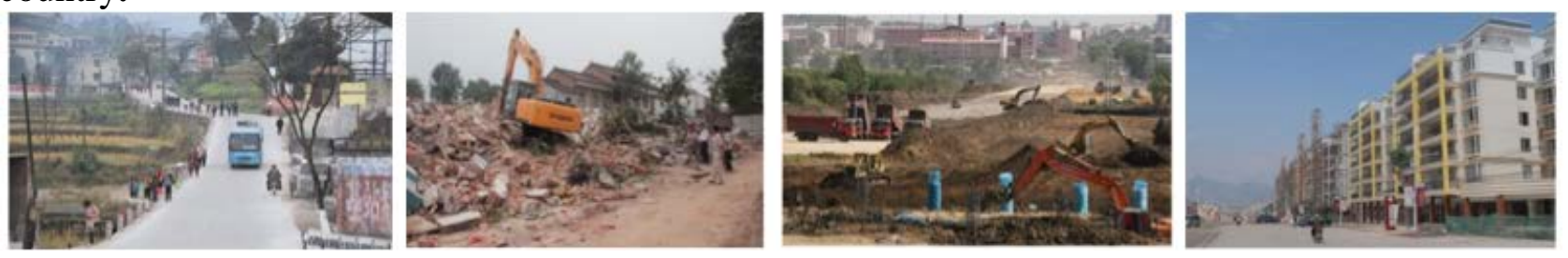

Figure.1The Development Process of North Yujia in Yantai

Furthermore, below, in Figure 2 the identities of these places are no longer distinguishable. Such phenomena is still ongoing at a fast pace in China, which leads to the urgent requirement for related research to be carried out in order to protect the originality of the country.
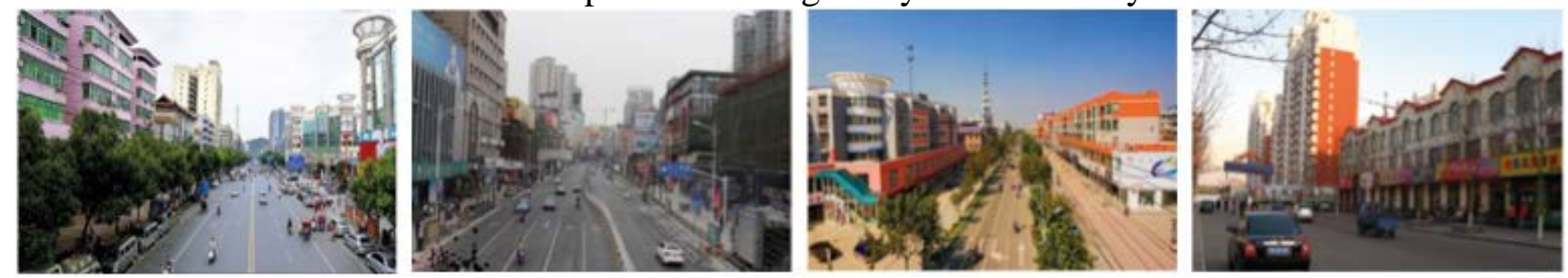

Figure.2 New Districts of FourDifferent Cities: different cities with new physical appearance

\section{Mass Migration between Cities Destroys the Original City Identity}

In recent years, the accustomed diversity of the population living in the old city has changed in China. The mass migration between cities caused the settlement of different groups, from different regions of the country, with different cultural characteristics that they had brought with them when they came to the city. Such phenomenon has boosted the city's urban development in a fast but disordered pace, because the design and planning failed to catch up the pace of how the city is 
developing. Several cities have spread consensus regarding the conversion into a global city such as Shanghai and Beijing. This resulted in a massive loss of the original city identity as they try their best to catch up with the western countries, which are crowed with concrete jungles, making those cities to start to look alike.

\section{Urban Design Works Better Suit the Financial Needs}

Currently in China, when planners or designers carry out the urban planning project or the urban design work, their major concern is always to better suit the investors' or government' financial needs, which is normally to maximize the space used to boost the revenue from the work. Hence, lack of planning and even design has always been a major problem in Chinese urbanisation, which results in homogeneous local structural and functions, which have an irreparable effect on local identity. Figure 3 explicitly shows the problem that China is facing --- loss of uniqueness.
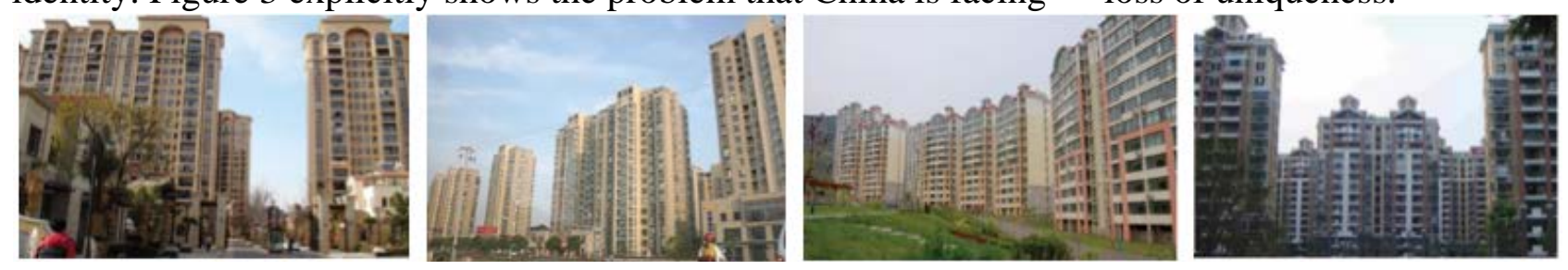

Figure.3Similar ResidentialAreas in Different Cities

\section{Change the Planning Freely to Improve Personal Political Reputation.}

Since 2000, Chinese urban landscape has started to suffer from fast construction plan alterations. Each newly elected government would halt any ongoing constructions that were approved by the previous government leaders and start a new plan to express their view on the local development issue to better improve their political reputation. This has also resulted in duplicated local images. For example, almost every major city would have a "public park" and "business venue" and "image of the city" architecture. Hence, One of the current urban planning and urban design trends in China is for cities to generate "Cityscape" plans. These plans are not required by the urban planning law but many city governments are commissioning them to both better represent their city and help guide its competitive future. However, the focus for those "Cityscapes" is majorly concerned with building new high-rise architecture more outstanding than the rest, rather than revamping the city's heritage or integrating the current local identity to better represent the city.

There are a lot of elements that have been ignored by Chinese local government during their city's revamping processes: The geographical features of the city; A major factor that differentiates "identical" cities is the historical cultural heritage; Historical architectural heritage; and The crucial component that drives all the aspects of local uniqueness is, of course, people [27].

As areas of towns and cities become increasingly similar, with high buildings and urban squares prominent on many urban streets, there is growing recognition that places, which retain character and local identity, are developing a competitive advantage. They score in terms of visitor economy success and as desirable places to live, work and spend leisure time in. This has led to the emergence of new disciplines around defining and managing the identity of a place, and new thinking about initiatives to improve the appeal of urban areas. Improvements to the character of an area and initiatives that aim to enhance local identity need to be communicated effectively as part of an overall marketing strategy if their full benefits are to be felt and a return on investment realised. Towns and cities now commonly use place marking as a strategic approach to the promotion of their area in the competition for visitors, investors, residents and businesses [28].

\section{Conclusion}

In the past 20 years China has been experiencing the largest scale urbanisation in its history. Because the urbanisation process started without solid planning there are many defects still on the way and there is a deep concern on how the country could maintain its dramatic development speed 
along with the protection of its own local identity. The practice of other global projects shows that various manifestations of local identities can be a valuable tool to support civic pride and to create an image for a place. A good local identity is a major force to bind and attract people and businesses as well to support the cities in engineering social and economic transformation of urban areas. Therefore, it is vital for China to know its own identity and act accordingly to either protect the identity or further develop it to support people's needs or attract more people and gain global competitiveness.

Over the next 20 years, future development will become better and better in China; it is essential for China to find the correct conceptt and method to solve itstheoretical and practical obstacles in its urbanisation progress. How to create local identity for rapidly transforming Chinese cities is an acute and fundamental issue. Therefore to find a way to identify the actual uniqueness at each region or local site, and then integrate the elements accordingly to make the cities stands out via its own heritage would be a beneficial step to the country's urbanisation process in the future. There is no simple way to combat the problem. One would need to compare different sites, new uses, events, and results of efforts to anchor the past identity in different ways and, over a period, observe the changes of identity of the former sites and the effects provoked by changes over time. These efforts and results need to be seen in a wider context of local identity development, or redevelopment, management of identities of other cultural heritage sites, and even of the cultural diversity of China.

\section{References}

[1] CHRISTMANN, G. B. 2003.StädtischeIdentitätalskommunikativeKonstruktion. Institute for Advanced Studies.

[2] SELMAN, P. \& SWANWICK, C. 2010. On the Meaning of Natural Beauty in Landscape Legislation. Landscape Research, 35, 3-26.

[3] LIN, G. C. S. 2002. Hong Kong and the globalisation of the Chinese diaspora: a geographical perspective. Asia Pacific Viewpoint, 43, pp63-91.

[4] HALL, S. 1997. Representation : cultural representations and signifying practices. London: SAGE.

[5] DEFFNER, A. 2007. Place marketing, local identity and cultural planning: The CultMark INTERREG IIIc project. Discussion Paper Series, 13, 367-380.

[6] PRITCHARD, A. \& MORGAN, N. J. 2001. Culture, identity and tourism representation: marketing Cymru or Wales? Tourism Management 22, 167-179.

[7] DREDGE, D. \& JENKINS, J. 2003. Destination place identity and regional tourism policy. Tourism Geographies, 5, 383-407.

[8] LEWICKA, M. 2011. Place attachment: How far have we come in the last 40 years? Journal of Environmental Psychology, 31, 207-230.

[9] RAAGMAA, G. 2002. Regional Identity in Regional Development and Planning 1. European Planning Studies, 10, 55-76.

[10] PAASI, A. 2003. Region and place: regional identity in question. Progress in Human Geography, 27, 475-485.

[11] OKTAY, D. 2002. The quest for urban identity in the changing context of the city: Northern Cyprus. Cities, 19, 261-271.

[12] SHAO.Y, LANGE.E, THWAITES.K, Defining and Identifying Local Identity, $52^{\text {nd }}$ WORLD CONGRESS INTERNATIONAL FEDERATION OF LANDSCAPE ARCITECTURE, June 7-15, 2015 
[13] LYNCH, K. 1960. The image of the city. Cambridge: MIT Press.

[14] HIDALGO, M. C. \& HERNANDEZ, B. 2001. Place Attachment: Conceptual and Empirical Questions. Journal of Environmental Psychology, 21, 273-281.

[15] ZUBE, E. H. 1991. Environmental psychology, global issues and local landscape research. Journal Of Environmental Psychology, 11, 321-334.

[16] JACOBS, J. 1961. The death and life of great American cities. New York: Random House.

[17] CARMONA, M., TIESDELL, S., HEATH, T. \& Oc T., 2003. Public Places Urban Spaces: The Dimensions of Urban Design. Oxford: Elsevier.

[18] OKTAY, D. 2005. How can urban context maintain urban identity and sustainability?: Evaluations of Taormina (Sicily) and Kyrenia (North Cyprus). the Intenational Conference for Integrating Urban Knowledge and Pactice. Gothenburg, Sweden.

[19] KINOSHITA, I., BINDER, H. \& OKABE., A. 2012. Identity and sustainability, towards new ways of urban redevelopment in an age of shrinking cities.Yasumasa Tani: HOBUNSYA Publisher. Inc.

[20] AMIN, A. \& THRIFT, N. 1994. Globalization, institutions, and regional development in Europe. Oxford : Oxford University Press.

[21] RELPH, E. 1976.Place and placelessness, London : Pion.

[22] CHEN, W. 2006. The lack of innovative theoratical system in modern city construction Chinese national Ministry of construction.

[23] YU, K., the art of living: locating the contemporary landscape architecture. Journal of architecture, 10, 39-43.

[24] YAN, G. \& TAO, W. 2009. The local identity of modern landscape design. Theory of Art and Design, 2, 81-83.

[25] WU, L., 1996, the science of human settlements, Urban Development Research, 1996 (1):15.

[26] WU, L., 2005, Regional planning and the creation of human living environment, Urban Development Research, 2005, 12(4): 1-6.

[27] BRYCE, W. B. 2012. Experiences with Chinese City Identity. In: CARRUS, G. (ed.) The 22nd IAPS Conference. Glasgow.

[28] CHEN, F. \& THWAITES, K. 2013. Chinese urban design : the typomorphological approach. Farnham: Ashgate. 